\title{
ON SHAPELINGS AND CHILDLINGS: A LINGUISTICS APPROACH TO THE EMERGENCE OF NEW CULTURAL BORDERS BETWEEN THE UNBORN AND THE NEW-BORN CHILD IN EME (1500-1700)
}

\author{
Paloma Tejada-CALler \\ Universidad Complutense de Madrid \\ ptejadac@filol.ucm.es
}

\begin{abstract}
This contribution aims at exploring the emergence of early-age stereotypes in Early Modern England from a Cultural Linguistics approach to Age Studies, using the Historical Thesaurus of the Oxford English Dictionary as a corpus. Results demonstrate that during the sixteenth and seventeenth centuries a new intersubjective conceptualization of embryos and new-borns emerged in English, confirming a more general social perception of the child as an autonomous human being. Moreover, the combined analysis of newly created synonyms for both embryos and infants in Early Modern English (EME) seems to suggest the existence of a temporary cultural understanding of infancy, later failed by the preponderance of science over subjective perceptions. Under this EME construal the current borders separating the unborn and the new-born seem to have been remapped.
\end{abstract}

Keywords: Early Modern English, Age Studies, Childhood, Cultural Linguistics, Lexicon. 


\title{
SHAPELINGS Y CHILDLINGS: SURGIMIENTO DE NUEVAS FRONTERAS LINGÜÍSTICO-CULTURALES ENTRE EL NIÑO NO NACIDO Y EL RECIÉN NACIDO EN INGLÉS MODERNO TEMPRANO (1500-1700)
}

\begin{abstract}
RESUMEN. El objetivo de este trabajo es analizar la aparición de estereotipos relacionados con las primeras etapas de la niñez desde la perspectiva de la Lingüistica Cultural, utilizando como corpus el Historical Thesaurus del Oxford English Dictionary. Los resultados demuestran que durante los siglos XVI y XVII surge en inglés una nueva conceptualización intersubjetiva de embriones $y$ recién nacidos, que confirma una percepción social del niño como "ser humano autónomo" más general. Junto a ello, el análisis combinado de los sinónimos que aparecen en inglés moderno temprano para referirse a embriones y a recién nacidos parece sugerir que durante el Inglés Moderno Temprano existió una interpretación cultural de la infancia temprana de naturaleza transitoria, según la cual las fronteras conceptuales que separan actualmente a los niños no nacidos de los recién nacidos se verían modificadas. Esta interpretación desaparecería en siglos posteriores, debido al papel cada vez más preponderante que ha jugado la ciencia sobre las percepciones subjetivas en lo que se refiere a la representación de las categorias afectadas.
\end{abstract}

Palabras clave: inglés moderno temprano, Age Studies, Infancia, Lingüística cultural, Léxico.

Received 31 January 2020 Revised version accepted 12 July 2020

\section{INTRODUCTION ${ }^{1}$}

From a twenty-first century position, it may be tempting to assume that the definition of life stages is fixed and unchanging; that is, that notions like childhood, youth, adulthood and later life are chronologically defined or age-based universal concepts. Moreover, a contemporary -and most likely weIRD-biased $-^{2}$, mindset may hinder the perception of a different mapping of borders separating apparently clear-cut categories such as the unborn and the new-born child. However, the belief that the definition, even the existence of specific life-stages is conditioned by ideological changes, cultural values and socially shared expectations is becoming an ever more salient tenet in the social sciences and the humanities. The efforts to unearth the complexities of this assumption have been increasingly growing since the 1990s and frequent calls for theoretical innovation and interdisciplinary

1 This work was supported by the Spanish Research Project Ref: FFI2016-77540-P 2016- The author is also grateful to the anonymous reviewers of her manuscript, who referred her to Wild 2010 and provided not only a careful reading of the paper, but generous comments and insightful suggestions. 2 WEIRD is an acronym for "western, educated, industrialized, rich and democratic", often used in social studies (Azar 2010: 11; Henrich 2010; Brookshire 2013). 
ON SHAPELINGS AND CHILDLINGS: A LINGUISTICS APPROACH TO THE EMERGENCE OF NEW CULTURAL..

approaches have been recurrently made in the scholarly literature. (Settersen 2003, 2007; Charise 2014; Katz 2014; Segal 2014; Pickard 2016, among many others).

At the same time, there seems to be academic consensus that Linguistics has failed to adequately address age and age-stage related concerns thus far. The dearth of studies focusing on age as a research theme, and not merely as a social marker, has led some scholars to assert that Linguistics has been "age-blind" until very recently (Eckert 1997; Coupland et al. 1991; Coupland 2009). Indeed, as a science much underutilized in social and humanistic studies, Linguistics has been slow in responding to the age-challenge, a practice that has directly affected the linguistic definition of life-stages (Tejada 2019a). And furthermore, whereas the call to integrate more language-centred analyses in the understanding of life stages and age identities (Nikander 2009) seems to have recently triggered a list of scattered investigations from various approaches (Bait 2009; Coupland 2009; Love 2011; Benczes et al. 2017; among others), most recent contributions are focused on midlife and later-life experiences affecting present-day citizens, as a response to the increasing concern on old age and its social effects. This implies that the lack of linguistic commitment to life-stage research becomes more blatant when the gaze is turned on childhood, historical understandings of life stages, or both.

Following this train of thought and to minimally redress the gaps of research identified above, the present study constitutes a further contribution to a longterm project focusing on the linguistic conceptualization of EME childhood from a Cultural Linguistics approach. More particularly, it intends to dive more deeply into the lexicographical and cultural conceptualization of EME infancy as a coherent childhood sub-stage. Our contention is that both the emergence of new lexical stereotypes separating the unborn and the new-born from the young child, and the consideration of the unborn and the new-born categories together, away from contemporary delineations, may reveal hidden socio-cognitive construals of the earliest stage of life in EME. The study draws on previous results obtained in Tejada (2018) and Tejada (2019b), where linguistic evidence was provided that a historical "discovery of childhood" would have occurred in English during the period 1500-1700, thereby ratifying what had been previously argued in the social sciences.

This study is divided into 5 sections, as follows. After the introduction, Section 2 will be devoted briefly to review the cultural construction of childhood. In Section 3, the theoretical tenets and methodological procedure driving this study will be succinctly exposed. Section 4 comprises the analysis and discussion of results obtained concerning the notions of ['child' as EMBRYO] and ['child' as INFANT], further suggesting the cross-border category of the [vulnerable sMall PeRSON]. The main concluding remarks will be included in a final Section 5 . 


\section{THE CULTURAL CONSTRUCTION OF (HISTORICAL) CHILDHOOD}

The child allegedly constitutes a recent topic in academic social discourse. There seems to be academic agreement that it was only after the release of Phillipe Ariès' pioneering and contentious essay, translated into English as Centuries of Childhood: A Social History of Family Life (1962), that the child was discovered by historians, becoming thereby not only an autonomous object of historiography, but a cultural category (Frijhoff 2012; Ferraro 2012; among others). Since the 1970s and much more clearly since the turn of the century, essays advocating a move away from nature in favour of cultural understanding of childhood have sprouted, directly or indirectly following Ariès' scheme of thought (Qvortrup et al. 2009; Fass 2012; Biddle 2017; Wyness 2018; among many others). However, to date most studies on childhood focus on social issues and contemporary socially demanding concerns. And, as hinted above, there is still little or no trace of purely linguistic pondering.

The scarcity of cultural definitions of past childhoods has been even more severe. Although the ground-breaking tenets put forward by Ariès specifically concerned the so-called discovery of childhood in Renaissance Europe, it is the past reconstruction of this notion that seems most slippery. Assertions that up to very recently childhood has been a "forgotten category" in the life-course, or the "silent" and obscure years in the social sciences (King 2007; Frijhoff 2012) gain full meaning when applied to history. Not only is there still a lack of studies concerning pre-adulthood in the past (Settersen 2007; Mawhinney 2015); scholarly depth also seems to fluctuate by historical period and childhood substage. Various factors seem to be at work in this context. First, any definition of past childhood presents specific problems to the contemporary scholar, one of the most significant being the blurry connection of childhood with age. It is well known that in pre-industrial societies, age-stages were not finely grained, (Mintz 2008), childhood and youth representing "fluid categories that are given definition and meaning by their social, cultural, political, institutional, locational, governmental, and economic contexts" (Wyn 2015: 1). Secondly, the speculative clash between childhood -as a socially-shared conceptual category- and the actual reality of children's past lives has not only been responsible for the wide controversy initially unleashed on the validity of Ariès' tenets (Pollock 1990; Heywood 2001; Orme 2001; Lowe 2004; Cunningham 2006; Dekker et al. 2012; Retford 2016; among others); it has also unbalanced the nature of historical research. It is on children, rather than past construals of childhood, that information is largely to be found. And moreover, it is not uncommon that evidence must be tracked indirectly. Frequently, children come up as secondary characters in historical works devoted to a diversity of topics, from 
the economic development of the family through to education ideologies and types of schooling, or child-labour conditions (Thane 1981; Fawcett 2005; Berry and Foyster 2011; the Routledge series Women and Men In History, etc.). As a consequence, research turns difficult when it comes to trace specific discussions on conceptual perceptions of childhood.

In conjunction with this, academic works privilege most recent historical periods. As expected, the abundance of nineteenth-century data, likely concurrent with a new legal concern about children and an emergent marketing of childhood (Denisoff 2008), has made of this stage the centre of greatest attention. This implies that lower levels of evidence make it more difficult to generate hypotheses. Likewise, not all childhood developmental stages have received equal consideration along time. In this case, it is prototypical children or children between three and their teenage years that have drawn widest interest. As for EME infants in particular, historical attention may be said to have concentrated on death rates and infanticide accounts thus far. It is only recently that an increased awareness of infants has been raised by gender and medical scholars focusing on mothering, child sickness, and further histories of women's lives, experiences and emotions. Researchers like Spivack (2007), Copeland (2008), Harrington (2010), Spence (2011), Scott (2013), Newton (2014), Wiedenbeck (2015) or Zeiter (2018), among others, have newly contributed key insights to the understanding of historical pregnancy and early childhood. It is to them that this article is much indebted.

The above-mentioned reasons may explain why linguistic research into the social perception of EME childhood has been almost non-existent and, more precisely, why very little has been explored to date to determine whether there is linguistic evidence on the discovery of childhood in England, expanding Ariès' proposal. This topic was tackled in Tejada (2018, 2019b). In Tejada 's first essay, a lexicographical model was devised to assess whether there was any linguistic hint of a new modern intersubjective conceptualization of childhood during the EME period. Drawing on the premise that the EME conceptual category 'child' might be reconstructed using a lexicographical approach, a table of new HTOED ${ }^{3}$ synonyms and word senses associated to the senses of ['child' as PERSON] was produced, to which a list of similar terms applying to ['child' as EMBryo] was added, considering that the first OED definition for 'child' with reference to state or age is "The unborn or the newly born". ${ }^{4}$ Synonyms were interpreted as markers of meaning profiles, the assumption being that examined together, they would be revelatory about the thinking of a society (Cf. Kay 2010).

3 HTOED stands for the Historical Thesaurus of the Oxford English Dictionary.

4 Cf. "child, n." OED Online, Oxford University Press, September 2019, www.oed.com/view/ Entry/31619. Accessed 12 September 2019. 
Results in Tejada (2018) confirmed the corpus as a coherent set of terms providing cumulative evidence of a clear change in the perception of childhood. Seemingly, by the eighteenth century childhood was no longer a blurred stage defined in terms of youth and short stature, but a category encompassing different sub-stages, each anchored around well-defined lexical stereotypes, and delineated along distinct features; a man-boy would have become gradually separated from the lap-child, before a child-in-arms and a womb-infant got more neatly profiled. Though requiring further discussion, the existence of a woman-girl also came up into the EME lexical typology of childhood identities as the female counterpart of the man-boy, if only in contrastive terms. All in all, findings confirmed an EME re-evaluation of childhood in social practice, reflecting a strengthening of emotional ties and a highly subjective appraisal. In this initial construal of children as autonomous human beings, the lap-child and the man-boy were revealed as the two most conspicuous sub-categories, their core value being mirrored in a most profuse lexical sketching. It is probably not random that these two prototypical identities, as it were, have been the focus of most forthcoming discussions.

Unlike prototypical children, the identities of the ['child' as EmBryo] and ['child' as INFANT] have remained somewhat peripheral to research. According to Astbury (2016) "we know very little about the earliest part of life in Early Modern England". It is not only that in the effort to split childhood from adulthood research into this sub-stage may have been thought unnecessary, granting that the difference between infancy and adulthood was clearest; the connection between the confined child and the delivered new-born baby may also have passed unnoticed to the contemporary mind, given the unchallenged role birth has progressively acquired as a major turning point in the life-cycle. It is to counterbalance these insufficiencies that this article comes up, bearing in mind Hall's 1983 statement that "culture has always dictated where to draw the line separating one thing from another (as in Dahl 2004). These lines are arbitrary, but once learned and internalized they are treated as real. More particularly, this study addresses a combined analysis of the initial phases of childhood, before and after birth, as drawn from the lexicon. It aims hence at expanding and reconsidering what was already stated in Tejada (2019b) adopting a fresh crossbordering perspective. In this line, research questions may be stated as follows: Is there any lexical evidence to assert a difference between the born and the unborn? In which terms? Are babies in any way different from older children? Is there any connection between the unborn and the new-born as inferred from lexical creativity? 
ON SHAPELINGS AND CHILDLINGS: A LINGUISTICS APPROACH TO THE EMERGENCE OF NEW CULTURAL..

\section{THEORETICAL TENETS AND METHODOLOGICAL STRATEGIES}

To assess whether a new intersubjective conceptualization of embryos and babies emerged in EME and further explore to what extent the lexicon enlightens the existence of new categories remapping the borders between pregnancy and infancy as we perceive them today, we followed the model in Tejada (2018) to analyse the rate and nature of lexical and semantic innovation registered in the HTOED, restricting it to the categories of the ['child' as EMBRYo] and the ['child' as INFANT], and informed the results with further social and historical readings.

Behind the model lie three central tenets of Cultural Linguistics. First, the idea that human conceptualization (that is, cognitive processes of schematization and categorization that serve as patterns of understanding and reasoning), is as much a collective as it is an individual phenomenon. Second, conceptualizations change through time and across groups of identity. And third, conceptualizations are alleged to be largely transmitted through language; putting it more plainly, language is seen as a collective memory bank for cultural conceptualizations (Wierzbicka 1997; Bartmiński 2009b; Mierzwińska-Hajnos 2010; Sharifian 2011, 2014; among others). The abovementioned view of language linking Cultural Linguistics and Ethnolinguistics to a sustained tradition stemming from Sapir $(1921,1957)$ stresses the idea that "vocabulary is a very sensitive index of the culture of a people" (Sapir 1957: 34, 36; Brinton and Closs-Traugott 2005; Ibarretxe-Antuñano 2007; Bartmiński 2016). The assumption that the vocabulary of a language constitutes the institutionalization of social meaning, words representing access nodes to shared knowledge, implies that lexicographical studies are deemed adequate to explore whether sixteenth- and seventeenth-century English shows "new conceptual categories, schemas, and propensities for certain perspectives" on infancy reflecting the cultural cognition of those who spoke the language at the time (Tomasello 1999: 169).

The steps followed in this study may be summarized as follows. After a global assessment of ['child' as EMBryo] and ['child' as INFANT] synonyms registered in the HTOED from Old English to the twentieth century, a closed corpus of sixteen new words and word senses (i.e. extended meanings of pre-existing words) emerging in the sixteenth- and seventeenth-century associated with the two child meanings in focus was compiled. Then, to obtain quantitative and qualitative results, the terms were analysed following the previously devised chart of twenty-four study parameters, including stylistic and axiological information, register connotations obtained from cross-reference definitions of the terms, etc. (Cf. Appendix 1). Also, in order 
to identify the degree of lexical and semantic innovation occurred during the Renaissance, the period was divided into eight 25-year subcategories, from period 1 (1500-1525) through to period 8 (1676-1700). For a qualified assessment of each term, the analysis required not only a close reading of definitions and dictionary labels, but also frequent cross-reference acts through the dictionary and the thesaurus. The study finally entailed the reading of secondary literature on midwifery manuals, the development of embryology, the perception of pregnancy, and EME notions of abortion, in an ever-richer literature building history from below.

\section{EME LEXICAL NOVELTY FOR THE ['CHILD' AS EMBRYO] AND ['CHILD' AS INFANT]}

As shown in Tejada (2018) the period 1500-1700 confirms a remarkable growth of new terms and extended meanings to refer to the five selected subcategories of ['child' as PERSON]..$^{5}$ In global terms, the general analysis of EME childhood vocabulary shows a clear index of novelty. However, the distribution of novelty is not balanced in quantitative terms. As shown in chart 1, neither embryos nor infants represent core categories of the new EME conceptualization of childhood, their synonyms representing $6 \%$ and $11 \%$ of innovation, respectively. EME attention seemed to be rather focused on children older than two.

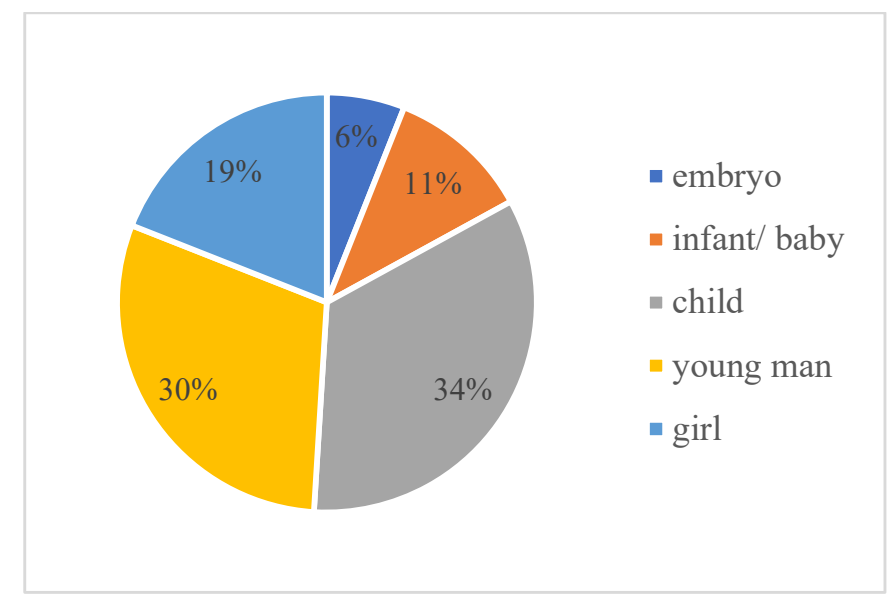

Chart $1.16^{\text {th }}-17^{\text {th }}$ century innovation per child-meaning.

5 ['child' as EMBRYO]; ['child' as INFANT]; ['child' as CHILD]; ['child' as young MAN]; ['child' as GIRL]. 
At the same time, innovation concerning embryos and babies seem to take place comparatively late in the period (1651-1675), that is, after a new conceptualization of young men and older children was well on its way. A new portrayal of young men, lexically stereotyped as the man-boy, reached momentum in period 4 (1576-1600) and that of the so-called lap-child (also called the two-year-old) in periods 4 and 5 (1576-1625). However, the lexical innovation for embryos and babies seem to explode during the mid-seventeenth century (Cf. chart 2)

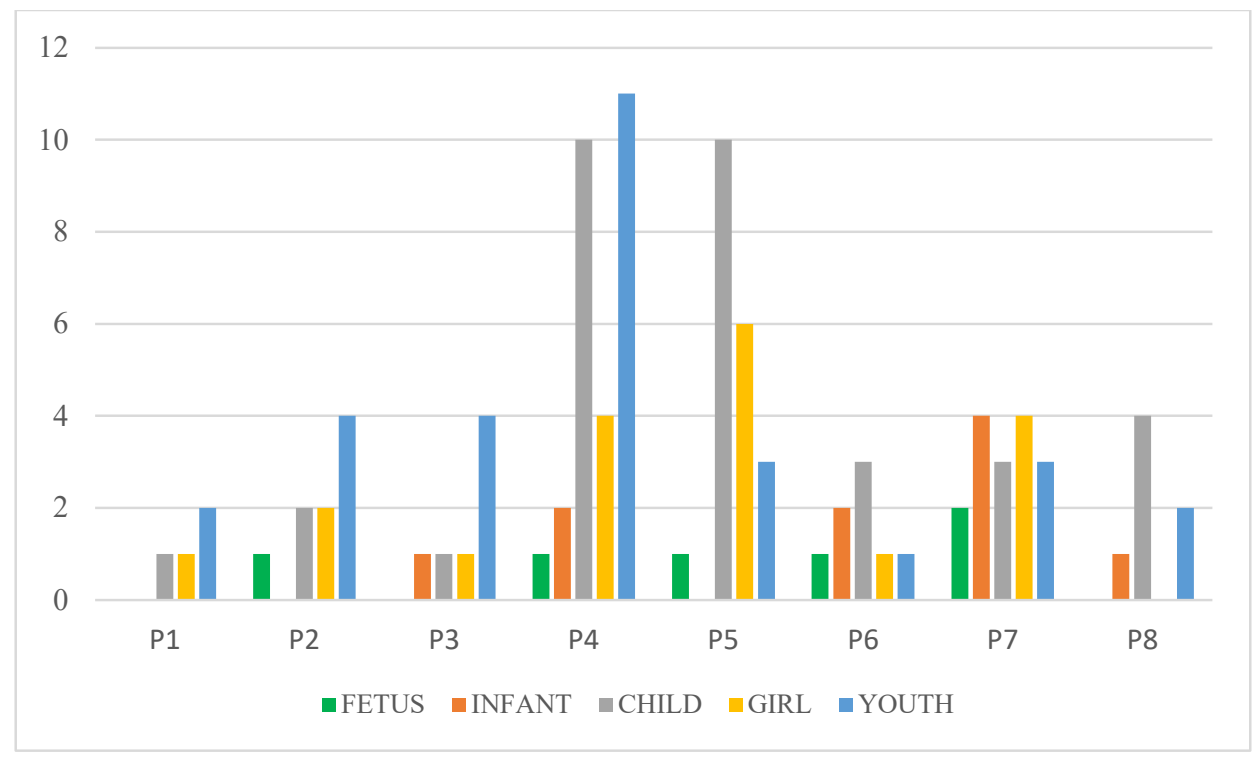

Chart 2. Lexical and semantic innovation per child meaning and time-period.

With regard to vocabulary changes, table 1 schematizes the terms featuring lexical or semantic innovation for both ['child' as EmBryo] and ['child' as INFANT] during the period under scrutiny. Two new words or senses for 'embryo' appear in English during the sixteenth century, namely feture and embryo, while the remaining four synonyms come up during the 1600s: womb-infant, hans in kelder, geniture and shapeling. As for 'infant', chrisomer, chrisom and tenderling are registered in the HTOED as sixteenth-century innovations, prior to a higher level of novelty in the seventeenth century, encompassing childling, flosculet, bratling, lullaby-cheat, stranger, child-in-arms and boppet. 
Table 1. New synonyms registered for ['child' as EmBrYo] and ['child' as INFAnT] in the HTOED for the period 1500-1700.

\begin{tabular}{|l|l|l|}
\hline \multicolumn{1}{|c|}{ PERIOD } & \multicolumn{1}{|c|}{ EMBRYO } & \multicolumn{1}{c|}{ INFANT } \\
\hline $1500-1525$ & - & - \\
\hline $1526-1550$ & feture (1540) & chrisomer (1574-5) \\
\hline $1551-1575$ & embryo (1576) & $\begin{array}{l}\text { chrisom (1596) } \\
\text { tenderling (1587) }\end{array}$ \\
\hline $1576-1600$ & womb-infant (1611) & $\begin{array}{l}\text { childling (1648) } \\
\text { flosculet (1648) }\end{array}$ \\
\hline $1601-1625$ & bans-in-kelder (1640) & $\begin{array}{l}\text { bratling (1652) } \\
\text { child in arms (1675) } \\
\text { lullaby-cheat (1665) } \\
\text { stranger (1674) }\end{array}$ \\
\hline $1626-1650$ & geniture (1672) \\
shapeling (1674) & boppet (1695) \\
\hline $1651-1675$ & \multicolumn{2}{|}{} \\
\hline
\end{tabular}

The corpus also informs that just half of the new synonyms for 'embryo' constitute new terms (rather than meaning extensions or reinterpretations of existing words), whereas this figure rises to $70 \%$ of new terms created to refer to the ['child' as INFANT].

As for the degree of obsolescence, according to the OED, 83\% of the newly created terms for 'embryo' are currently obsolete and over $80 \%$ of the EME new synonyms for 'infant' are either obsolete or rated as rare in current use. ${ }^{6}$ Hence, EME creations for both 'embryo' and 'infant' may be said to have been short-lived, an insight already pointed out by Glover (2018: 56) in passing: "many of the terms used in the EME period are unfamiliar to modern readers because they eventually fell out of fashion and were replaced". Yet, no further discussion is offered.

\subsection{THE ['CHILD' AS EMBRYO]}

Though scarce in absolute terms, lexical or semantic innovation in the sixteenth- and seventeenth century represents $55 \%$ of the total number of synonyms compiled in the HTOED for this category along history. From the Old English period to the fourteenth century embryos were referred to through the

6 According to the OED, by the eighteenth century chrisomer and bratling had fallen out of use; chrisom, tenderling, stranger, hoppet disappeared in the nineteenth century, and lullaby-cheat and flosculet apparently represent the shortest-lived terms for infants. As for foetuses, only the term embryo has survived. 
ON SHAPELINGS AND CHILDLINGS: A LINGUISTICS APPROACH TO THE EMERGENCE OF NEW CULTURAL...

general term child. It is only in scientific discourse that some direct borrowings from the Classical languages had been introduced at the turn of the fifteenth century (fetus 1398 and embryon 1400). Further fourteenth-century terms, specifically fruit of the loins (1340) and conception (1398), entailed a vague meaning, aligning human embryos with those of animals, plants or any other creature and false fruits that might possibly grow in the womb (Spivack 2007: 9; Buklijas and Hopwood 2014). Moreover, according to the OED, fourteenthcentury terms for embryos focused on the idea of 'progeny' or 'offspring', a major social concern widespread in medieval times (Fawcett 2005). Emphasizing embryos either as future inheritors or as progenitors of lineage, these terms blurred the difference between the born and the unborn. ${ }^{7}$

As drawn from the corpus, a growing number of words for the unborn child becomes ever more visible from 1576 onwards. This reflects an increasing social awareness and interest in the establishing of boundaries, likely triggered by the development of embryology in Early Modern England. According to Glover (2018), this was a time of great change when English practices and traditions regarding conception, pregnancy, and childbirth widely developed.

From 1576 onwards, new terms and word senses for embryos seem to be divided into two stylistic registers: namely, the specialized and the familiar level, the latter being of particular interest in this study. An initial lexical innovation in the specialized field is carried out through borrowing from Latin or French, a predictable move, considering the marked increase experienced in the translation of midwifery and medical books from the late sixteenth-century onwards (Astbury 2017; Glover 2018; Carrillo Linares 2018). As described in the OED, this is the case of feture, embryo and geniture (a term close to conception in French, generally referred to the generation of an animal or plant). The EME creations exhibit a very low degree of novelty, representing close variations from the already existing terms fetus and embryon. A subtle yet interesting- restriction of sense is apparently observed in the words feture and geniture, evolving into "embryo or foetus", from a wider idea of "offspring". It should be stressed that the semantic emphasis in these words was laid on the underdevelopment of beings, not necessarily human, before they got the features of their species.

7 According to the OED, a fetus was the "offspring of a human or other animal during its development within the uterus or egg. In later use: spec. the developing offspring". In turn, fruit of the loins is defined as "offspring, progeny. Also, an embryo, foetus". And conception as "that which is conceived in the womb; an embryo, fetus; a child, offspring". Likewise, it should be noted that the cultural notion of progeny was responsible for a good deal of medical interest in the womb, according to Buklijas and Hopwood 2008; medical doctors were tightly connected with inheritance laws, and had an expert say on the birth of legitimate heirs, who would decide the destinies of families and states. 
However, during the sixteenth and seventeenth centuries there seems to arise in England a familiar perception of embryos, channelled by the nativization of vocabulary, the introduction of popular metaphors or both. As we know it from the OED, the word shapeling, a diminutive apparently confected by Fairfax ${ }^{8}$ to refer to animals and plants as living entities "getting shaped", provides evidence of contemporary attempts to nativize foreign vocabulary concerning embryos. According to Glover (2018), ${ }^{9}$ the vernacular writing of medical and midwifery manuals apparently escalated from the mid-seventeenth century, a moment directly connected with the Royal Society's puritan project of linguistic renewal, characterized by the desire for plain, native style and the reaction against Latinism and scholastic obscurity (Connor 2019). No matter how restricted its use, the nativized word shapeling would certainly have contributed to rendering embryos more clearly and immediately perceptible to the socially-shared knowledge. Also, the diminutive formative -ling in shapeling would bring about the idea of smallness -already present in terms like embryo- to a new realm of domesticity and popular interpretation.

Closest to popular knowledge, a different perception of embryos seems to emerge from the two remaining terms, womb-infant and hans-in-kelder. Familiar metaphors of confinement are perceived in womb-infant. The defining term womb would be hastily interpreted as a container, an image also elicited in the more complex hans-in-kelder, the latter implying a second metaphorical level. But furthermore, a strict distinction seems to arise between these terms and the former feture, embryo, fetus, and shapeling. The presence of the term infant and the name hans as word-forming elements in these expressions should be underscored as lexical indexes of personhood; that is, of a fresh awareness of embryos as human beings. This leads us into the concept of 'quickening', a major cultural notion in EME, referring to the first perceptible movements of the fetus during pregnancy. According to Scott (2013: 82), "quickening held a place of huge significance within the complex 'conceptual scheme' of pregnancy, where 'when the child was felt to move... its life had begun'”. Similarly, Müller (2012) asserts as common belief "that when the unborn child had formed extremities like arms and legs it signified personhood" (see also McClive 2002; Zeiter 2018: 2). Hence, the moment when the foetus was formed and animated seems to constitute a turning point among the EME society marking that the not-yet-human had turned a child. Key to this conventional interpretation of personhood is that before 1800 pregnancy of a human child was only legible to mothers. Consequently, it is the mother's

8 For Nathaniel Fairfax and his views on language, cf. Connor 2019.

9 See also Astbury (2017: 503), citing Mary E. Fissell's estimation that by 1700 there was one vernacular medical work in circulation in England for every four families. 
inner individual experience, turning the embryo into a child, that also triggers the creature's recognition as a public category (Buklijas and Hopwood 2014; Glover 2018; Steinway 2018). This formulation buttresses the significance -both private and public- of such terms as womb-infant and hans-in-kelder. Speculatively, these terms would constitute a landmark incident, wherefrom all individual and socially shared expectations linked to procreation would be unchained.

Our contention in Tejada (2019b) was that the emergence of descriptive and metaphorical expressions in the familiar register would mostly contribute to expand the new intersubjective conceptualization of the embryo category as different from the new-born child. To our view, womb-infant would operate as an anchoring word; that is, a descriptive term denoting a particular sub-stage which stood in contrastive relationship to other focal terms sketching the human childhood lifecycle. However, womb-infant goes well beyond this interpretation. It apparently establishes a new category, the viable human child, as decided by the mother. In other words, the recognition of the embryo as a person links this creature to the supra-category of childhood, removing it from that of foetus. A womb-infant or hans-in-kelder is no longer a developing creature, but a confined child. By the eighteenth-century boundaries have apparently become established between medical and popular shapelings and womb-infants. As the lexicalization of a childhood stereotype, womb-infants would anchor the unborn child as a [PERSON FOETUS] in contrast to other categories or identities of childhood.

In historical terms, this EME construal seems to constitute a transitory cultural framework, later failed by the greater attraction exerted by science over the subjective perception in the construction of early life-stages. Linguistic results show that after the EME period the construction of embryos gradually moves into a present-day interpretation. From the eighteenth century onwards, the central EME notion of the preborn child as a confined person gradually fades away, overridden by that of a child in development and not fully shaped, birth subsequently gaining strength as a major turning point. A quick look into the lexical change occurring along the past two hundred years confirms that most popular EME creations for embryo fall into disuse; only two new synonyms appear in the twentieth century, both reinforcing the contemporary idea of a not-fully formed and developing creature: pudding and bun in the oven.

Summarizing the above, EME new terms for embryo constitute two most important advances in the separate conceptualization of childhood sub-stages with respect to the medieval period. First, in the seventeenth century the unborn child seems to gather fresh attention, creations showing a strengthening of emotional ties and a new separate concern, away from the previous instrumental attitude that portrayed embryos as offspring. And second, under the new cultural scheme, 
a new stereotype is created, that of the womb-infant, recognising the transition from womb to light; yet this stereotype plays a provisional twofold role: not only does it establish a difference between the embryo and the new-born child; it also links preborn children to the newly-born.

\subsection{THE ['CHILD' AS INFANT]}

Moving on into the next childhood sub-stage, the ['child' as INFANT] emerges as a late perception, similarly to what happened to the ['child' as EmBryo]. It is only from the seventeenth century onwards - once the categories of 'child' as lapchild and 'child' as man-boy had been distinctly identified- that a more explicit discernment of babies is proved, through the creation of an increasing number of new synonyms.

Assessed in relative terms, innovation in this category exhibits the largest degree of lexical creativity in the period. Casting a detailed view on the corpus, we observe that $70 \%$ of the total amount of synonyms for ['child' as INFANT] constitute new coinages, which might lead to the conclusion that this sub-stage represents an intended invention. Delayed in time, there seems to be an acute need for Early Modern contemporaries to assert these creatures as distinctively different from their older counterparts, stereotyped as the two-year-old or lap-child.

Not surprisingly, before the sixteenth century babies were referred to through the most general term child, or through foreign -also rather vague- terms introduced from French in the fourteenth century. That would be the case of infant, defined in the OED as "A child during the earliest period of life (or still unborn)", from which two short-lived, somewhat expressive derivations came up: fauntekin, fauntelet, both most likely restricted to French-speaking contexts and elites. Alongside, baban, babe had also emerged in the fourteenth century as natural creations reproducing infantile vocalization, with the still too vague meaning "very young child", "a child of any age". ${ }^{10}$ Last, a nativized baby surfaced at the turn of the fifteenth century showing "considerable overlap with babe", according to the OED. It is in the mid-fifteenth century that a more subjective conceptualizing tendency tentatively appears, with the creation of words like the dialectal and short-lived lakin ("plaything") and the semantic expansion of mop, a term of uncertain origin and obscure etymology, formerly meaning 'fool' or 'simpleton'.

However, from the sixteenth century onwards a distinctively vernacular lexicalization of babyhood is perceived away from French, and furthermore, both

10 It is to note the Latin meaning of infant as a non-speaking child, explaining the prevalence of this image in the construal and lexical portrayal of new-borns. 
a more complex and precise portrayal of this childhood sub-stage emerges. The situation in the sixteenth and seventeenth centuries seems to confirm that during this period babies aroused an increasingly greater social interest in England, promoting not only the nativization of the lexicon for this stage but also a neatly profiled identity, largely cast in emotional subjective terms.

From a qualitative perspective, results show that the conceptualization of EME babyhood moves apparently from a religious description to a more expressive and evaluative perception, lexicalized in native terms. At the beginning of the period, the lexicon seems to mirror a social pressure to publicly ratify the newborn in religious terms. Though the term chrisom was already in use as the first element of such compounds as chrisom child or chrisom babe, the creation of new independent nouns like chrisomer (in period 3: 1551-1575) and chrisom (in period 4: 1601-1625) suggests not only a plain insistence on the religious innocence of babies (symbolically represented by the white robes at baptism), but also a wish to reinforce the official recognition of the child at church, preventing the parents from unwanted legal consequences in case of an untimely death of the child. An indication of the parents' concern, the terms chrisom or chrisomer allowed the institutional identification of a new-born not only different from still-borns, but also from objects of infanticide.

As for subsequent lexical creations concerning the ['child' as INFANT], both a move away from institutional attention and a more physical and descriptive definition is appreciated. The baby appears to be increasingly understood and conceptualized as a small and fragile being, as illustrated by tenderling, childling, flosculet or bratling. ${ }^{11}$ Considering the prior existence of child and brat as correlate synonyms for the category of two-year-olds, these formations are probably best described as denotational diminutives, evaluating size over bare affection. Accordingly, the new construal of new-borns would stress their physiological distinction from older children focusing on infants' small size and tender bodies (Newton 2014). Moreover, this lexical weight on physical tenderness in tenderling may reveal ever more meaningful, in the face of the EME extended practice of swaddling babies to protect their limbs until the age of two.

Notwithstanding the above, it is also important to note that, as diminutive formations, childling, tenderling, bratling or flosculet add to the large collection of expressives that characterizes the new global conceptualization of childhood in Early Modern England. ${ }^{12}$ As shown in Tejada (2018) during the period under

11 According to the HTOED, these expressions, as well as lullaby-cheat, hoppet, child-in-arms, chrisom or chrisomer, are restricted to babies under two years of age during this period. Childling expands its meaning to refer more generally to "a little child" in 1903.

12 I have taken the term "expressive" from typological scholarship (Tufvesson 2007; Steriopolo 
study almost $80 \%$ of the terms newly applied to the notion of childhood could be classified as expressives. The ['child' as INFANT] would be no exception.

Much in line with this tendency towards subjectivity, a final phase of innovation in the EME lexicalization of infants comprising metaphorical perceptions of babyhood is perceived. A combination of affection and description of daily behavioural routines, the cant and dialectal expressions lullaby-cheat and boppet ("a child danced in the arms") explicitly depict new-borns as distinct from the lap child. Daily cares and attention towards new-borns and older children would certainly require different activities adequate to either identity. In turn, (little) stranger introduces a different nuance in the social construction of EME infants. Through this playfully used term, a new-born seems to be further construed as a not yet well-acquainted visitor, someone not seen before, in clear contrast to the confined womb-infant. To this respect, it should be noted that up to the eighteenth century there were no available images or pictures of an evolving embryo (Buklijas and Hopwood 2014). A metaphorical perception of infants is also observed in the above-mentioned flosculet ("little flower"). Despite the scarcity of data, the presence of flosculet in the present corpus might arguably reinforce the lexical dividing line between babies and older children. As described in the above-mentioned study, two-year-olds were most often represented by animal metaphors, plants being more conspicuous in the symbolic construction of EME male adolescents.

Last in our account of EME new infant synonyms, the term child-in-arms contributes the most descriptive and objective social construction of infants. Also, the most historically stable. This expression becomes the best candidate to act as an anchoring word, or stereotype, around which the whole characterization of identity revolves. Stereotypically, an EME child-in-arms would be a child, unable to walk, requiring specific caring actions, smaller and more tender than the lap-child. Not too surprisingly, it is their size and inability to walk that persists in many of the new synonyms generated in forthcoming centuries.

The above-mentioned remarks help us conclude that in the seventeenth century the definition, the perception and the way people felt about babies had changed. As a child-in-arms, a baby seems to have been construed as a small child in need for special care and arising affection. It is their size, their frailty and their inability to walk that separates babies from older children, a category that had already been perceived as autonomous and depicted along similar lines of intimacy and fondness.

2016) to encompass diminutives, nicknames, metaphors, sound-symbolism, alliterative terms and terms indicating emotions, attitudes and evaluations. 
ON SHAPELINGS AND CHILDLINGS: A LINGUISTICS APPROACH TO THE EMERGENCE OF NEW CULTURAL..

\subsection{A REMAPPING OF BORDERS?}

The late recognition of infants as different from older children and the significant lexicalization of viable foetuses as 'children' may speculatively suggest a remapping of cultural borders in the Early Modern understanding of earliest childhood. Lexical innovation in the seventeenth century may hint at the existence of a transitory category connecting infants to the viable unborn, and highly linked to both the mother's experience and a disrupted household space. This definition of infancy not against adulthood but against the not-yet-born may well have passed unnoticed to the contemporary researcher, unconsciously driven by their own predefined taxonomies and assumed stability of embryos and babies and as "social types". As stated above, the idea of childhood seems ultimately dependent on common ways of thinking about life-stages. Far-removed from scientific and objective indicators, EME pregnancy and infancy appear to have been contingent to a female awareness and concern, dragged along a stretched process, extending from the recognition of personhood at quickening to the survival of the child after its first year of age. In this line, the EME womb-infant and the "tiniest child of tender limbs" might represent a joint cultural category of [VULNERABLE SMALL PERSON], unknown to us. Both socially and individually, the period comprising the latest stages of pregnancy and the first year of life would be felt as a precarious stage in Early Modern England, a site of unpredictable and sudden changes endangered by the threat of death. Hence, it might be argued that the triumph over menacing death would represent a more categorical turning point than birth itself. Moreover, the tentatively advocated EME childhood sub-stage would constitute a time when the symbiotic relationship between mother and child reached its highest degree, and boundaries between the inside body and the outside world were experienced as thinnest. According to social and medical historians, mother and child would face a "rough and long passage" before and after birth (Pollock 1990; Astbury 2017: 518-519). And furthermore, having babies was perceived as an ongoing process that did not end with the birth of a child, but -we may argue- with the overcoming of death. It should be recalled that not all EME new-borns would become children or youth, a condition bringing infants closer to foetuses in practice and thought. On the one hand, death rates topped their highest levels during the first year of age. On the other, the borders between a new-born, a stillborn and an abortion remained blurred, considering the number of undeliberate or conscious killings of children at birth, first-year infanticides, abandonments and further fortunes experienced by not-yet-borns and new-borns alike (Spivack 2007; Ferraro 2012; Scott 2013; Glover 2018). Under these circumstances, the two-year-old would constitute a more factual landmark, the prototypical EME turning point in the perception of infancy. The collective mind would feel that around this age the child had safely become 
a social child, beyond the individual experience of maternity, globally construed. And the reverse, womb-infants, childlings, and tenderlings could not be said to belong to public life, staying yet peripheral to it (Laoutaris 2013). This would explain the EME late need to lexicalize this experience, establishing a clear-cut stereotype of the ['child' as INFANT] as a child-in-arms, separate from older children and connected to the human unborn. A stronger awareness that life depended on care -as perceived in diaries, letters, narratives and midwifery books (Spivack 2007; Astbury 2017; Glover 2018)- would explain the strengthening of emotional ties, lexicalized in terms representing both viable embryos and infants as objects of increasing affection and concern.

Before concluding, a brief note on the short-lived nature of EME expressions thus far considered seems pertinent. As has been noticed, a high proportion of words defining infancy during the sixteenth- and seventeenth century appear to be popular and emotional formations. Similar to what occurred in the vocabulary of core sub-stages of childhood, the lexis of infancy proves deeply connected with subjectivity and intimacy. Though further research is needed, in the case of infancy this may imply that we are attending an incipient moment of vocabulary creation in the colloquial and informal edges of language, reflecting private needs to mark off a time of strong "emotional toll" that would be endured within the household walls (Astbury 2017: 513). It is this local and private nature of innovation that may explain why the EME lexicon for infancy did not have a lasting effect on the language, words being either rejected or ignored by the later speech community. Future scientific understandings of the lifecycle would combine with further public policies to bring up a new childhood construal and lexicalization, this time institutionalized from above.

\section{CONCLUDING REMARKS}

This project adds to the increasing number of lexicographical studies that have been pursued in the last ten years based on the HTOED, yet with other purposes. This case has ultimately confirmed the utility of the OED and the HTOED as tools to expand linguistic research to areas conventionally covered by the social sciences, starting thereby a creative interdisciplinary dialogue of mutual gain.

More particularly, our study has explored the existence of linguistic evidence supporting a new EME construal of infancy, an apparently overlooked life stage along the English Linguistics space. Findings have shown that neither embryos nor babies constitute universal, predefined categories, but cultural constructions. The 
analysis of lexical and semantic innovation concerning the concepts of ['child' as EMBRYO] and ['child' as INFANT] in EME has demonstrated that new common ways of thinking about these two sub-stages of childhood emerged at the time. Though in quantitative terms, neither embryos nor infants seem to typify core categories in the conceptual transformation of childhood, the lexically neat delineation of both embryos and infants reflect a significant qualitative transformation in cognitive and social patterns.

As for embryos, they are no longer reduced to the scientific realm or to the wider idea of progeny. Alongside, there seems to arise a more familiar perception of these entities, channelled through vernacular words and popular metaphors of size and confinement. However, it is the construction of embryos as [PERSON] through such terms as womb-infant or hans-in-kelder that proves most significant. Concerning infants, results seem to confirm that during EME babies aroused an increasingly greater social interest in England, promoting not only the nativization of the lexicon for this stage but also a neatly profiled identity. The perception of babies moves from an institutional need to assert the new-born in religious terms, to more subjective notions of vulnerability, physical helplessness and dependency in terms of smallness, tenderness and inability to walk, commonly brought about through metaphorical expressions.

Finally, linguistic data may suggest a remapping of borders in EME, corroborating what has been put forward in recent social and historical studies. Jointly considered, the existence of the expression two-year-old as a synonym for the lap-child, the deferred need to creatively separate new-borns away from older children, and the presence of word-formations like womb-infant and hans-in-kelder, seem to open up a cognitive and cultural EME provisional framework that would alter the current borders delineated by birth as major turning-point in the life-cycle. To the EME mind, a distinct childhood identity, that of [vulnerable small person], would be marked by the threat of death and the split between the private space of infancy and the social space of older children. In historical terms, the triumph of a scientific mindset would gradually stress the idea of embryo as a not-fully-formed developing creature, establishing birth as the relevant turning point and gradually realigning infancy with the notion of early childhood. It goes without saying that the exploratory nature of the present study invites further linguistic research into the definition of historical childhood identities, and more particularly into the definition of infant identities raised in periods where pregnancy, still-births or death were not as clearly delineated as they are today. 


\section{REFERENCES}

Ariès, P. 1962. Centuries of Childhood: A Social History of Family Life. New York: Vintage.

Astbury, L. 2016. "Bawling babies and their baths in early modern England", Welcome Library blog. <http://blog.wellcomelibrary.org/2016/06/bawlingbabies-and-their-baths-in-early-modern-england/>. (12/12/2019)

Astbury, L. 2017. "Being Well, Looking Ill: Childbirth and the Return to Health in Seventeenth-century England". Social History of Medicine 30 (3): 500-519.

Azar, B. 2010. "Are your findings 'WEIRD'?" Monitor on Psychology 41(5).

Bait, M. 2009. "Discursive representations of old age in geriatric editorials". Identities across Media and Modes: Discursive Perspectives. Eds. A. James and G. Garzone. Bern: Peter Lang. 289-310.

Bartmiński, J. 2009. Aspects of Cognitive Ethnolinguistics. London and Oakville, CT: Equinox.

Bartmiński, J. 2016. "Ethnolinguistics in the Year 2016". Ethnolinguistic 28: 9-31.

Benczes, R., Burridge, K., Sharifian, F. and K. Allan. 2017. "Cultural linguistics and ageing: What naming practices in Australian English can reveal about underlying cultural conceptualizations". Advances in Cultural Linguistics. Ed. F. Sharifian. Springer. 607-624.

Berry H. and E. Foyster. 2011. The family in Early Modern England. Cambridge: University Press.

Biddle, S. K. 2017. "Social Constructions of Childhood: From Not-Yet-Adults to People in Their Own Right”. Anthós 8 (1): article 3.

Brinton, L. and E. Closs-Traugott. 2005. Lexicalization and Language Change. Cambridge: University Press.

Buklijas T. and N. Hopwood 2008 (2014). An Online Exhibition Making Visible Embryos. <http://www.hps.cam.ac.uk/visibleembryos/s5_3.html>.

Carrillo Linares, M. J. 2018. "Difusión del conocimiento médico a través de las lenguas vernáculas en la Inglaterra bajomedieval: una aproximación dialectológica”. Cuadernos del CEMyR 26: 203-227.

Charise, A. 2014. "The Future Is Certain: Manifesting Age, Culture, Humanities". Age, Culture, Humanities 1: 11-16.

Copeland, S. C. 2008. Constructions of infanticide in Early Modern England: female deviance during demographic crisis. MA dissertation. Ohio State University.

Coupland, N., Coupland, J. and H. Giles, eds. 1991. Language, society, and the elderly: discourse, identity, and ageing. Oxford, UK: Basil Blackwell. 
ON SHAPELINGS AND CHILDLINGS: A LINGUISTICS APPROACH TO THE EMERGENCE OF NEW CULTURAL..

Coupland, J. 2009. "Discourse, identity and change in mid-to-late life: interdisciplinary perspectives on language and ageing”. Ageing \& Society 29: 849-861.

Cunningham, H. 2006. The invention of childhood. BBC Books

Dahl, S. 2004. Intercultural Research: The Current State of Knowledge. Middlesex University Discussion Paper, 26. <https://ssrn.com/abstract=658202>.

Dekker, J. J. H. et al. 2012. "Discoveries of childhood in history: an introduction". Paedagogica Historica 48 (1): 1-9.

Denisoff, D., ed. 2008. The Nineteenth Century Child and Consumer Culture. Aldershot: Ashgate.

Eckert, P. 1997. "Age as a Sociolinguistic variable". The Handbook of Sociolinguistics. Ed. F. Coulmas, Oxford: Blackwell Publishers. 151-67.

Fass, P. S., ed. 2012. The Routledge History of Childhood in the Western World. Routledge.

Fawcett, M. 2005. "Historical views of childhood". Focus on early childhood: Principles and realities. Eds. M. Boushel, M. Fawcett and J. Selwyn. Oxford: Blackwell: 7-20.

Ferraro, J. M. 2012. "Childhood in Medieval and Early Modern Times". The Routledge History of Childhood in the Western World. Ed. P. S. Fass. London: Routledge.

Frijhoff, W. 2012. "Historian's discovery of childhood". Paedagogica Historica 48 (1): $11-29$.

Glover, V. E. 2018. "To Conceive With Child is the Earnest Desire if Not of All, Yet of Most Women": The Advancement of Prenatal Care and Childbirth in Early Modern England: 1500-1770. MA dissertation. Virginia Commonwealth University. <https://scholarscompass.vcu.edu/cgi/viewcontent. cgi?article $=6778 \&$ context $=$ etd $>$.

Harrington, R. 2010. "Pregnancy, childbirth and the female body in early modern Germany". Past and present 150: 84-110.

Heywood, C. 2001. A History of Childhood: Children and Childhood in the West from Medieval to Modern Times. Polity Press.

Ibarretxe-Antuñano, I. et al. 2007. "Introduction". Language, Mind and the Lexicon. Eds. I. Ibarretxe-Antuñano, C. Inchaurralde and J. M. Sánchez. Frankfurt, Peter Lang. 1-9.

Katz, S. 2014. "What is age studies?" Age Culture Humanities, 1. <http:// ageculturehumanities.org/WP/what-is-age-studies/>.

Kay, Ch. 2010. "Historical Thesaurus of the Oxford English Dictionary: Introduction". Cunning Passages, Contrived Corridors: Unexpected Essays in the History of Lexicography. Ed. M. Adams. Monza: Polimetrica. 
King, M. 2007. "Concepts of Childhood: What We Know and Where We Might Go". Renaissance Quarterly 60 (2): 371-407.

Laoutaris, C. 2013. Shakesperean maternities. Edinburgh University Press

Love, H. 2011. "Ageism, Language and the Law". SSRN Electronic Journal January: 2-19.

Lowe, R. 2004. "Childhood through the ages". An introduction to early childbood studies. Eds. T. Maynard and N. Thomas. SAGE: 65-75.

Mawhinney, S. E. 2015. Coming of Age: Youth in England, c.1400-1600. PhD thesis. University of York.

McClive, C. 2002, "The hidden truths of the belly: the uncertainties of pregnancy in early modern Europe". Social bistory of medicine 15 (2): 209-27.

Mierzwińska-Hajnos, A. 2010. "The Linguistic Worldview Revisited. A Cognitive Analysis of Plant Terms". Poznań Studies in Contemporary Linguistics 46 (4): 457-479.

Mintz, S. 2008. "Reflections on Age as a Category of Historical Analysis". The Journal of the History of Childhood and Youth 1 (1): 91-94.

Müller, W. 2012. The criminalization of abortion in the west: its origins in medieval law. Cornell: University Press.

Newton, H. 2014. The Sick Child in Early Modern England, 1580-1720. Oxford: University Press.

Nikander, P. 2009. "Doing change and continuity: age identity and the micro-macro divide". Ageing \& Society 29 (6): 861-879.

Orme, N. 2001. Medieval Children. New Haven and London: Yale University Press.

Pickard, S. 2016. Age studies: A sociological examination of how we age and are aged through the life-course. Sage Publications.

Pollock, L. 1990. "Embarking on a rough passage: the experience of pregnancy in Early Modern society". Women as mothers in pre-industrial England. $39-67$.

Qvortrup, J., Corsaro, W. and M. Honig, eds. 2009. Handbook of childhood studies, Palgrave Macmillan.

Retford, K. 2016. "Philippe Ariès's 'discovery of childhood': imagery and historical evidence". Continuity and Change 31 (3): 391-418.

Sapir, E. 1921. Language: an introduction to the study of speech. New York: Harcourt, Brace and World.

Sapir, E. 1957. Language. Culture, language and personality: Selected essays. Ed. D. G. Mandelbaum. Berkeley: University of California Press.1-44. 
ON SHAPELINGS AND CHILDLINGS: A LINGUISTICS APPROACH TO THE EMERGENCE OF NEW CULTURAL...

Scott, C. 2013. Birth Control and Conceptions of Pregnancy in Seventeenth-Century England. Retrospectives 2: 73-85.

Segal, L. 2014. "The Coming of Age Studies". Age, Culture, Humanities 1. <http:// ageculturehumanities.org/WP/the-coming-of-age-studies/>.

Settersten, R. A., Jr. 2003. "Propositions and controversies in life-course scholarship". Invitation to the life course: Toward new understandings of later life. Ed. R. A. Settersten, Jr. Amityville, NY: Baywood. 15-45.

Settersten, R. A., Jr. 2007. Passages to Adulthood: Linking Demographic Change and Human Development. European Journal of Population 23 (3): 251-272.

Sharifian, F. 2011. Cultural Conceptualisations and Language. Theoretical framework and applications. John Benjamins.

Sharifian, F. 2014. Cultural Linguistics. The Routledge Handbook of Language and Culture. Ed. F. Sharifian. London: Routledge. Chapter 32.

Spence, L. 2011. Women who murder in Early modern England 1558-1700. MA dissertation. University of Warwick.

Spivack, C. 2007. "To 'bring down the flowers': the cultural context of abortion law in Early Modern England". William and Mary Journal of Women and the Law 107: 1-39.

Steinway, E. 2018. "Narrating Pregnancy and Childbirth: Infanticide and the Dramatization of Reproductive Knowledge". Humanities 7: 120.

Tejada Caller, P. 2018. "A Cultural Linguistics approach to the discovery of childhood in sixteenth and seventeenth century Britain". Unpublished talk delivered on the public session called for the obtaining of Full Professorship at the UCM. (now in press for Token. A Journal of English Linguistics, 10).

Tejada Caller, P. 2019a. "Speakers as cultural insiders. Or what linguists may contribute to the idea of a "normal life'". Plenary lecture delivered at the IABAEurope conference (Madrid).

Tejada Caller, P. 2019b. "On new-borns and babies. The emergence of new lexical age-stereotypes in Early Modern England". Oral paper presented in the $V I$ Conference on Cultural Texts and Contexts in the English-Speaking World. University of Oradea.

Thane, P. 1981. "Childhood in History". Childhood, Welfare and Justice. Ed. M. King. Batsford. 6-25.

Tomasello, M. 1999. The cultural origins of human cognition. Harvard: Harvard University Press.

Tufvesson, S. 2007. "Expressives". Field Manual Vol. 10. Ed. A. Majid. Nijmegen: Max Planck Institute for Psycholinguistics. 53-58. 
Wiedenbeck, A. E. 2015. The natural mother. Motherbood, Patriarchy, and Power in Seventeenth-Century England. Unpublished PhD dissertation. Arizona State University.

Wierzbicka, A. 1997. Understanding cultures through their key words. New York: Oxford University Press.

Wild, K. 2010. "Angelets, trudgeons and bratlings: the lexicalization of childhood in the Historical Thesaurus of the Oxford English Dictionary". Cunning Passages, Contrived Corridors: Unexpected essays in the history of lexicography. Ed. M. Adams. Monza: Polimetrica. 289-308.

Wyn, J. 2015. "Thinking About Childhood and Youth". Handbook of Children and Youth Studies. Eds. J. Wyn and H. Cahill. Singapore: Springer.

Wyness, M. 2018. Childhood, Culture and society. SAGE Publications.

Zeiter, M. 2018. "El infanticidio como crimen y la historiografía europea. Primeras aproximaciones". Lecture delivered at the II Jornadas Nacionales de Historiografía. Facultad de Ciencias Humanas. Universidad Nacional de Río Cuarto. 
APPENDIX 1

\begin{tabular}{|c|c|}
\hline \multicolumn{2}{|c|}{ PARAMETERS } \\
\hline & New Word $(\mathrm{Y} / \mathrm{N})$ \\
\hline & Period \\
\hline \multirow[t]{6}{*}{ CHILD SENSES } & Embryo/ Fetus \\
\hline & Infant/Baby \\
\hline & Child \\
\hline & Girl \\
\hline & Young Man \\
\hline & Meaning \\
\hline \multirow[t]{3}{*}{ CURRENCY } & Currency: Obsolete \\
\hline & Last Quotation \\
\hline & Last Quotation after 1900 \\
\hline \multirow{2}{*}{$\begin{array}{l}\text { ZOOSEMY AND NATURE } \\
\text { METAPHORS }\end{array}$} & Plants \\
\hline & Animals \\
\hline \multirow[t]{6}{*}{ AXIOLOGICAL NUANCES } & Diminutive/ Hypocoristic \\
\hline & Contempt/ Depreciative \\
\hline & Affection/Endearment \\
\hline & Irony/Playful \\
\hline & Negative Overtone \\
\hline & Positive Overtone \\
\hline \multirow[t]{5}{*}{ STYLISTIC LABELS } & Slang \\
\hline & Coll \\
\hline & Regional/ Cant \\
\hline & Gendered \\
\hline & Uncertain/ Unknown/ Obscure Etymology \\
\hline
\end{tabular}

